\title{
Intrahepatic cholangiocarcinoma presenting as Budd-Chiari syndrome: A case report and literature review
}

\author{
Joanna K Law MD ${ }^{1}$, Jenny Davis MB FRCPC ${ }^{2}$, Anne Buckley MB FRCPC ${ }^{3}$, Baljinder Salh MB FRCPC
}

\begin{abstract}
JK Law, J Davis, A Buckley, B Salh. Intrahepatic cholangiocarcinoma presenting as Budd-Chiari syndrome: A case report and literature review. Can J Gastroenterol 2005;19(12):723-728.
\end{abstract}

Intrahepatic cholangiocarcinoma, an increasingly recognized primary tumour of the liver, is associated with a very poor prognosis. A patient with this tumour who presented with Budd-Chiari syndrome (the first to the authors' knowledge in Western literature and only the third patient overall) secondary to extensive thrombosis in his inferior vena cava extending from the right atrium down to his iliac vessels is described. Neither curative nor palliative intervention was deemed to be an option in this patient, who deteriorated rapidly while on anticoagulants. Postmortem examination confirmed the radiological findings, and histological analysis revealed characteristic appearances of this tumour within the biliary tree and invasion into the inferior vena cava. Furthermore, biliary dysplasia, which can be a precursor to this cancer, was also noted within some of the bile ducts.

Key Words: Budd-Chiari; Intrahepatic cholangiocarcinoma; Liver

\section{Cholangiocarcinome intrahépatique prenant l'aspect d'un syndrome de Budd-Chiari : Rapport de cas et revue de la littérature}

Le cholangiocarcinome intrahépatique, une tumeur primitive du foie de plus en plus reconnue, est associé à un pronostic très sombre. On décrit ici le cas d'un patient atteint d'une telle tumeur qui s'est présenté avec un syndrome de Budd-Chiari secondaire à une thrombose importante de la veine cave inférieure, s'étendant de l'oreillette droite aux vaisseaux iliaques (premier cas signalé dans la littérature occidentale à la connaissance des auteurs et troisième cas seulement au monde). Ni l'intervention curative ni les mesures palliatives n’ont été jugées envisageables chez ce patient dont l'état s'est rapidement détérioré alors qu'il prenait des anticoagulants. L'autopsie a confirmé les signes révélés à la radiologie et l'analyse histologique a pour sa part permis de vérifier les signes caractéristiques de cette néoplasie dans l'arbre biliaire et son envahissement vers la veine cave inférieure. En outre, la dysplasie biliaire qui peut être un signe précurseur de ce cancer a également été notée dans certains des canaux biliaires.
C holangiocarcinoma is a cancer of the gastrointestinal tract arising from the epithelial cells of the intrahepatic or extrahepatic bile ducts. Intrahepatic cholangiocarcinoma (ICC), often classified as a primary liver tumour, arises from the small biliary ducts and ductules, and typically presents as a focal liver mass. In one series of 77 patients with ICC over a 28-year period (1), presenting symptoms included abdominal pain $(83 \%)$, weight loss $(51 \%)$, anorexia $(46 \%)$, abdominal mass (22\%) and abdominal distension (23\%) - all nonspecific clinical symptoms that may suggest a variety of abdominal pathologies. Budd-Chiari syndrome (BCS), a group of disorders that results in the obstruction of blood flow out of the liver, is most commonly associated with a hypercoagulable state and tends to present with abdominal pain, hepatomegaly and ascites $(2)$. There have been two reported cases $(3,4)$ in the literature of cholangiocarcinoma in patients with BCS - the first was in a patient from a case series that attempted to etiopathologically classify BCS (3) and the second was in a woman who had presented with recurrent venous thrombosis (4). We present a patient with metastatic ICC presenting as acute BCS with a large tumour thrombus in the inferior vena cava (IVC) and plain thrombus extending from the right atrium down into the iliac veins.

\section{CASE PRESENTATION}

A previously healthy 70-year-old man presented to the emergency department with complaints of increasing shortness of breath, fatigue and nausea of six days' duration. Five months before presentation, the patient had a routine physical examination that was remarkable only for anemia; subsequent fecal occult blood testing was negative on three separate occasions and the patient was initiated on iron supplementation. An outpatient abdominal ultrasound was nondiagnostic, and arrangements for outpatient computed tomography (CT) scan and gastroenterology appointments were made. However, before either of these could occur, the patient presented to hospital with the above complaints in addition to an increase in abdominal girth along with a $4.5 \mathrm{~kg}$ weight gain over the six days.

The patient's past medical history was remarkable for hypertension treated with felodipine. The patient was an ex-smoker, having quit more than 15 years before presentation; there was also significant alcohol consumption of onehalf of a bottle of sherry and wine per day until one month before presentation.

Upon presentation, the patient was comfortable, afebrile, normotensive and anicteric, but tachycardic at 112 beats/min

Departments of ${ }^{1}$ Medicine, ${ }^{2}$ Pathology and ${ }^{3}$ Radiology, Vancouver Hospital and Health Sciences Centre, Vancouver, British Columbia

Correspondence and reprints: Dr B Salh, Division of Gastroenterology, University of British Columbia, \#100 - 2647 Willow Street, Vancouver,

British Columbia, V5Z 3P1. Telephone 604-875-5287, fax 604-875-5447, e-mail bsalh@interchange.ubc.ca

Received for publication June 13, 2005. Accepted June 14, 2005 


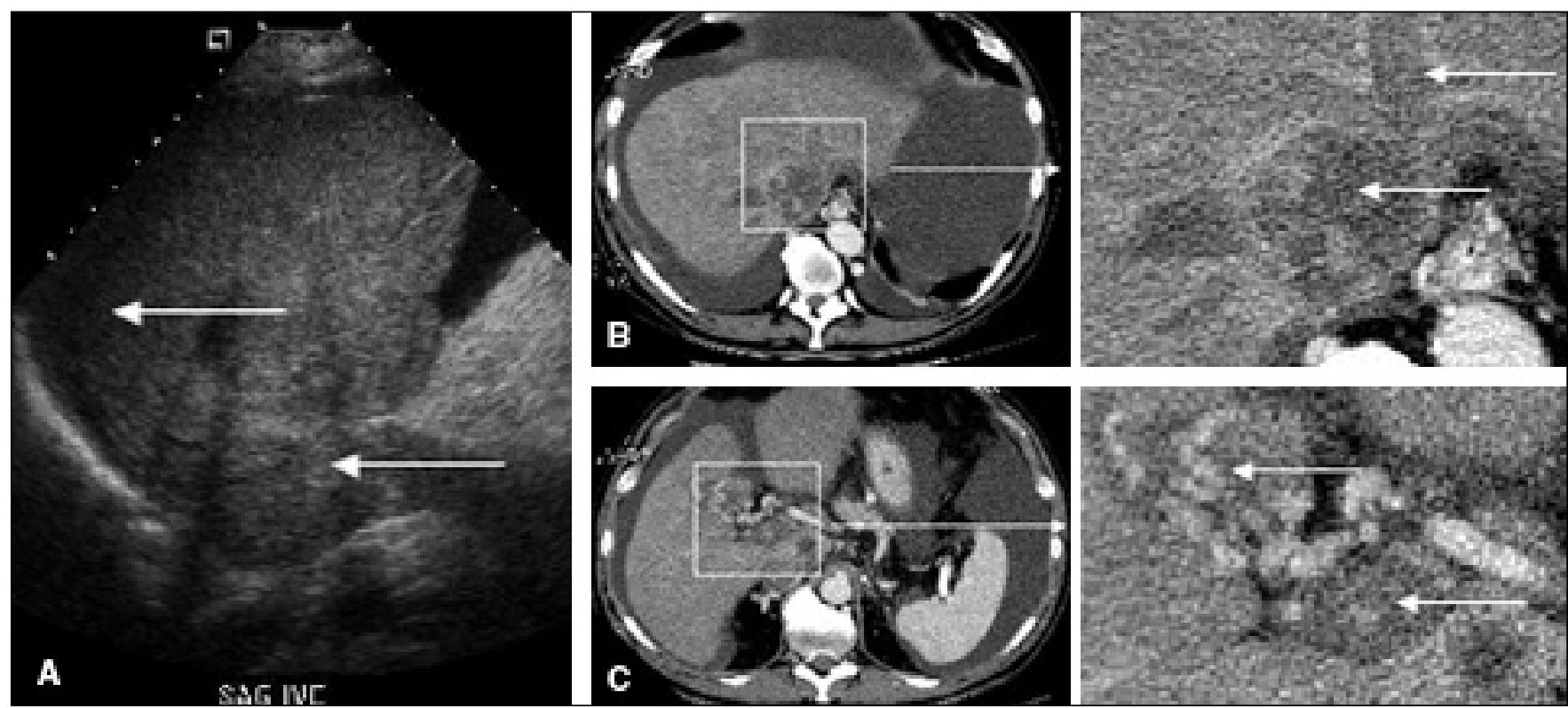

Figure 1) Ultrasound and computed tomography findings indicate substantial thrombosis affecting the inferior vena cava (IVC). A Ultrasound in the sagittal (SAG) plane depicting extensive thrombus in the IVC (lower arrow). The right lower lobe of the liver is also shown (upper arrow). B Computed tomography showing a thrombus within the IVC (inset, lower arrow) extending into the hepatic vein (inset, upper arrow). Ascites is also seen. The liver is noted to be otherwise normal without any focal mass lesion. C Computed tomography cut depicting cavernous transformation of the portal vein (inset, upper arrow) with portal vein thrombosis (inset, lower arrow)

with normal oxygen saturation on room air. Physical examination revealed a nontender, distended abdomen and clinical findings consistent with hepatomegaly and ascites without splenomegaly. Blood work on admission was most remarkable for elevated alanine aminotransferase, $1405 \mathrm{U} / \mathrm{L}$ (normal $25 \mathrm{U} / \mathrm{L}$ to $80 \mathrm{U} / \mathrm{L}$ ); aspartate aminotransferase, $1440 \mathrm{U} / \mathrm{L}$ (normal $10 \mathrm{U} / \mathrm{L}$ to $38 \mathrm{U} / \mathrm{L}$ ); bilirubin, $88 \mu \mathrm{mol} / \mathrm{L}$ (direct $44 \mu \mathrm{mol} / \mathrm{L}$, normal less than $18 \mu \mathrm{mol} / \mathrm{L}$ ); alkaline phosphatase, $145 \mathrm{U} / \mathrm{L}$ (normal $50 \mathrm{U} / \mathrm{L}$ to $200 \mathrm{U} / \mathrm{L}$ ); lactate dehydrogenase, $746 \mathrm{U} / \mathrm{L}$ (normal $90 \mathrm{U} / \mathrm{L}$ to $210 \mathrm{U} / \mathrm{L}$ ); and international normalized ratio, 1.8 (normal 0.9 to 1.20 ).

An abdominal ultrasound revealed no intra- or extrahepatic duct dilation. There were no focal liver lesions and the spleen was normal. There was significant ascites in addition to an extensive IVC thrombus that extended from the infrarenal level to above the diaphragm (Figure 1A). Portal vein thrombosis was also noted. The patient was then started on intravenous heparin infusion and an abdominal CT scan was arranged with biphasic imaging of the liver. The CT scan confirmed the presence of diffuse thrombus in the IVC from the right atrium to its bifurcation in the pelvis with portal and hepatic vein thrombosis (Figure 1B). Cavernous transformation of the portal vein was noted (Figure 1C). No discrete liver masses were identified and patchy changes in attenuation were attributed to perfusion abnormalities.

The patient was stable on room air and, despite an elevated coagulation profile, he was converted to oral anticoagulation. Investigations revealed normal levels of carcinoembryonic antigen and alpha-fetoprotein. Hepatitis A, B and C serology were all negative.

On the eighth day after presentation, the patient developed a significant thrombocytopenia with platelet counts dropping from $242 \times 10^{9} / \mathrm{L}$ to $22 \times 10^{9} / \mathrm{L}$ over three days (normal range $150 \times 10^{9} / \mathrm{L}$ to $450 \times 10^{9} / \mathrm{L}$ ) and was noted to have bright red blood per rectum. As the day progressed, he became increasingly short of breath and was noted to require oxygen supplementation to maintain saturation greater than $92 \%$. Later that evening, the patient developed significantly laboured breathing and blood gas analysis revealed a $\mathrm{pH}$ of 7.13 with a $\mathrm{pCO}_{2}$ of $24 \mathrm{mmHg}$ (normal $35 \mathrm{mmHg}$ to $45 \mathrm{mmHg}$ ) and a bicarbonate level of $8 \mathrm{mEq} / \mathrm{L}$ (normal $21 \mathrm{mEq} / \mathrm{L}$ to $28 \mathrm{mEq} / \mathrm{L}$ ); lactate was significantly elevated at $18.14 \mathrm{mmol} / \mathrm{L}$ (normal $0.5 \mathrm{mmol} / \mathrm{L}$ to $2.2 \mathrm{mmol} / \mathrm{L}$ ). The patient was then intubated and brought to the intensive care unit. Workup in the intensive care unit revealed multiorgan dysfunction. The patient developed anuric renal failure with hyperkalemia in addition to a disseminated intravascular coagulopathy picture that did not correct with the administration of fresh frozen plasma and vitamin $\mathrm{K}$. Additionally, on chest $\mathrm{x}$-ray, there was evidence of right upper lobe pneumonia, and examination of a peripheral blood smear showed many neutrophils with toxic granulation, suggestive of infection. Overwhelming sepsis was thought to be the source of the patient's decline and, as the patient became progressively hypothermic, there was a decision by family and health care providers to change the direction of care to palliation and the patient died the following morning of respiratory failure.

\section{Pathology}

Postmortem examination revealed prominent tumour extension into the IVC (Figures 2A and 2B) with central venous necrosis of the liver and a clot extending down into the iliac veins and cephalad into the right atrium (not shown). There was obvious tumour extending into the hepatic vein with a metastatic lymph node seen in the sagittal section (Figure 2C). There was additional extensive metastasis to periportal lymph nodes, the omentum, the serosa of the descending colon and the rectovesical pouch. Microscopic examination revealed an area adjacent to the IVC with necrotic carcinoma within a bile duct with more obvious malignant glands adjacent to the biliary wall (Figures 2D and 2E). Additional microscopic analysis 

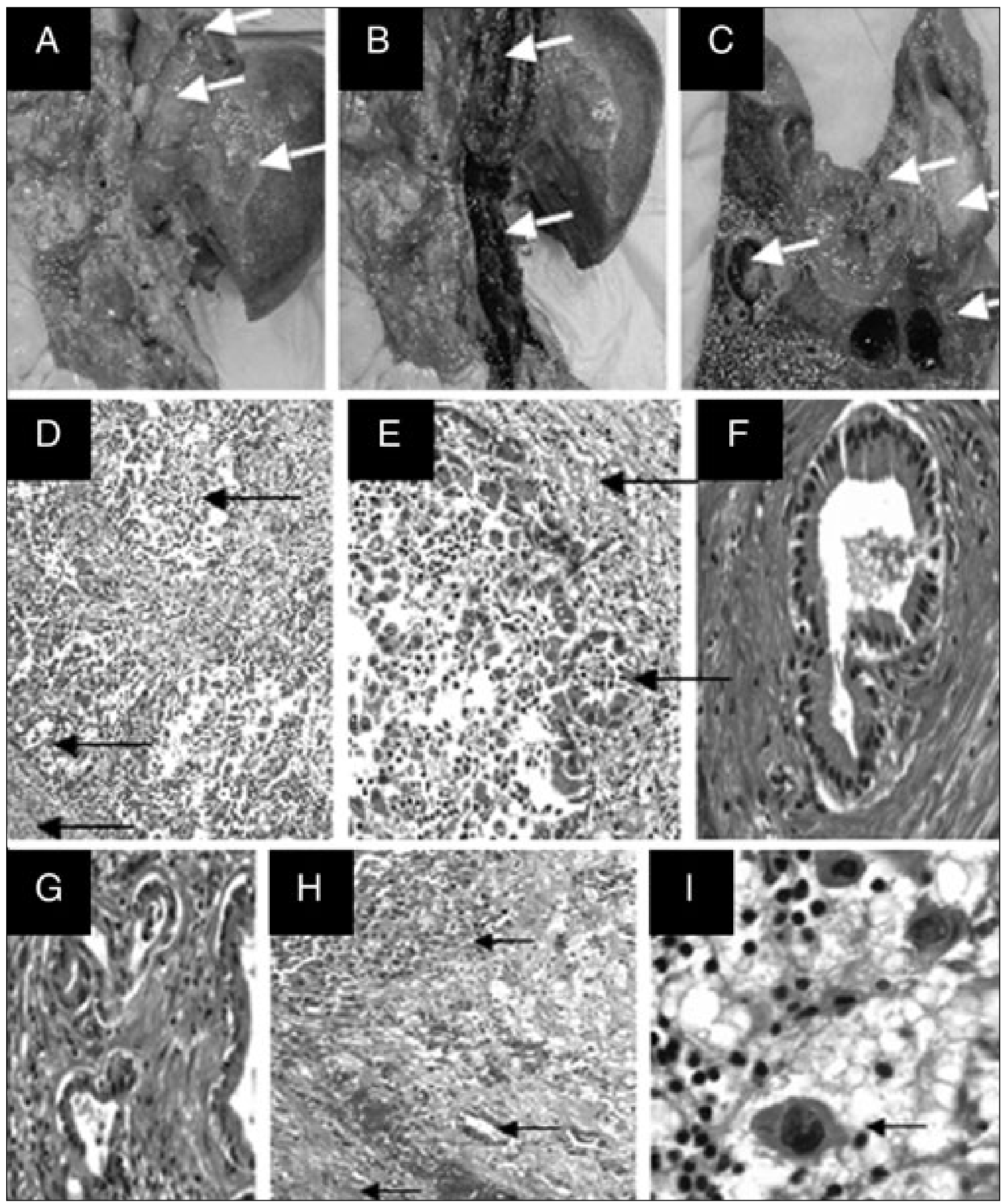

Figure 2) Macroscopic and microscopic features of the tumour. A Posterior view showing the tumour (upper arrow) arising from within the inferior vena cava (IVC) and extending downward (middle arrow). The lower arrow simply shows the liver. B The IVC has been cut revealing the extensive tumour (upper arrow) and clot extending downwards (lower arrow). C Section of the transverse plane revealing the tumour and thrombus in the hepatic vein (left arrow) and within the IVC (right, upper arrow), metastatic lymph node (right, middle arrow) and liver (right, lower arrow). D Section through a bile duct showing the necrotic tumour (upper arrow) and formed malignant glands (middle arrow), as well as the bile duct wall (lower arrow). E Tumour within the bile duct (lower arrow) and malignant gland (upper arrow). F Normal bile duct. G Dysplastic bile duct. H Section through the IVC revealing the necrotic tumour (upper arrow), glandular component (middle arrow) and the IVC wall (lower arrow). I Additional section revealing tumour cells within the IVC with altered nuclear morphology (arrow) 


\section{TABLE 1}

Radiological evaluation of cholangiocarcinoma

\begin{tabular}{|c|c|c|}
\hline Technique & Specific features & Note \\
\hline Ultrasound & $\begin{array}{l}\text { Depicts ICC as a mass lesion } \\
\text { Detects ductal obstruction in } 89 \% \text { of patients with surgical } \\
\text { obstructive jaundice } \\
\text { Provides sensitivity of } 94 \% \text { to correctly diagnose and establish } \\
\text { site of obstruction with specificity of } 96 \%(29) \\
\text { Enables vascular assessment with duplex ultrasound - } \\
\text { invasion of portal vein or hepatic artery is an important } \\
\text { prognosticating factor }\end{array}$ & $\begin{array}{l}\text { Malignant etiology is more common than benign causes with } 10.8 \% \text { of } \\
\text { diagnoses being cholangiocarcinoma } \\
\text { Hilar cholangiocarcinoma (Klatskin tumour) classically manifests as } \\
\text { segmental dilation and nonunion of right and left ducts at the } \\
\text { porta hepatis on ultrasound (30) } \\
\text { Papillary tumours resemble polypoid intraluminal masses } \\
\text { Nodular cholangiocarcinoma appears as a discrete smooth mass } \\
\text { associated with mural thickening } \\
\text { Infiltrating cholangiocarcinoma is most difficult to appreciate on ultrasound }\end{array}$ \\
\hline Dynamic CT & $\begin{array}{l}\text { Provides sensitive means of detecting intrahepatic } \\
\text { bile duct tumours }\end{array}$ & $\begin{array}{l}\text { CT scan finding of hypodense hepatic lesion with peripheral } \\
\text { enhancement, biliary dilation and contrast enhancement on delayed } \\
\text { images were highly suggestive of peripheral ICC (31) } \\
\text { Staging of hilar cholangiocarcinoma is not accurate for determination of } \\
\text { resectability } \\
\text { Overall accuracy for assessing resectability was } 60 \%(32)\end{array}$ \\
\hline MRCP & $\begin{array}{l}\text { Provides noninvasive technique for evaluation of intrahepatic and } \\
\text { extrahepatic bile ducts and pancreatic duct without contrast } \\
\text { administration } \\
\text { Provides useful adjunct to other radiographic diagnostic tools - } \\
\text { allows identification of any intrahepatic mass lesions and } \\
\text { evaluation of bile ducts above and below stricture }\end{array}$ & $\begin{array}{l}\text { Cholangiocarcinomas appear as hypointense lesion on T1-weighted } \\
\text { images, hyperintense lesion on T2-weighted images } \\
\text { Allows detection and preoperative assessment of bile ducts, vessels } \\
\text { and hepatic parenchyma (33) } \\
\text { In one series of } 126 \text { patients with suspected bile duct obstruction } \\
\text { undergoing MRCP, sensitivity was } 91 \% \text {, specificity was } 100 \% \text { and } \\
\text { overall accuracy was } 94 \% \\
\text { In patients with malignant obstruction, sensitivity and positive predictive } \\
\text { value were } 86 \% \text {, specificity and negative predictive value were } 98 \% \\
\text { and accuracy was } 97 \% \text { (34) }\end{array}$ \\
\hline EUS & $\begin{array}{l}\text { Allows visualization of local extent of primary tumour - } \\
\text { especially for distal bile duct lesions } \\
\text { Allows assessment of status of regional lymph nodes }\end{array}$ & $\begin{array}{l}\text { EUS appears more sensitive for detection of pancreatobiliary carcinomas } \\
\text { and assessment of portal venous invasion compared with } \\
\text { transabdominal ultrasound, CT scan and angiography in one series } \\
\text { of } 73 \text { patients (35) } \\
\text { Clinical experience for imaging and staging of proximal bile duct lesions } \\
\text { is still limited }\end{array}$ \\
\hline Cholangiography & $\begin{array}{l}\text { Acts as a diagnostic tool for visualizing site and extent of biliary } \\
\text { obstruction; other less invasive and equally accurate } \\
\text { tests are available }\end{array}$ & $\begin{array}{l}\text { Is useful to obtain diagnostic bile samples or brush cytology } \\
\text { Sampling of bile will result in positive cytology in about } 30 \% \text { of } \\
\text { cholangiocarcinomas, rising to between } 45 \% \text { and } 70 \% \text { when brush } \\
\text { biopsy and endoscopic biopsy are combined (36) }\end{array}$ \\
\hline
\end{tabular}

CT Computed tomography; EUS Endoscopic ultrasound; ICC Intrahepatic cholangiocarcinoma; MRCP Magnetic resonance cholangiopancreatography

revealed the presence of bile duct dysplasia remote from the tumour site (Figure 2G). Examination of the IVC sections revealed tumour cells with a glandular outline (Figure $2 \mathrm{H}$ ), as well as pleomorphic nuclei containing tumour cells (Figure 2I). In summary, the findings indicated cholangiocarcinoma of the large intrahepatic bile duct(s) with bile duct dysplasia.

\section{DISCUSSION}

Worldwide, there has been a noted increase in the incidence of ICC. In England and Wales, there was a noted 15-fold increase in age-specific mortality rates between 1968 and 1996, with ICC surpassing hepatocellular carcinoma (HCC) as the most common primary liver tumour in England in 1993 (5). A ninefold increase was noted in Scotland for the period between 1968 and 1997 (6). In the United States, there was a reported $165 \%$ increase in the incidence of ICC between 1975 and 1999 (7). Several factors have been postulated toward explaining the increasing incidence of ICC, including the development of better diagnostic tests (eg, endoscopic retrograde cholangiopancreatography [ERCP]), earlier diagnosis of tumours (and, thus, better outcomes because of diagnosis at an earlier tumour stage) and reclassification of hepatobiliary tumours. However, even before the use of ERCP in the 1970s, there was a noted trend toward an increasing incidence of ICC that has steadily increased with continuing use of ERCP and other diagnostic modalities. The specific radiological modalities useful for the diagnosis of cholangiocarcinoma are summarized in Table 1.

In a recent review of cholangiocarcinoma, Olnes and Erlich (8) noted the risk factors associated with this malignancy, including primary sclerosing cholangitis, choledochal cysts, hepatolithiasis, flukes and thorium dioxide exposure. However, most presentations of cholangiocarcinoma are idiopathic and tend to present in the seventh decade of life. Painless jaundice is the most common symptom of the more prevalent extrahepatic cholangiocarcinoma (hilar), a distinctly different clinical, therapeutic and epidemiological disease from ICC (9). The latter is commonly recognized as a primary liver tumour; it is 
the second most common primary liver tumour (second to HCC) and accounts for approximately $6 \%$ of all cholangiocarcinomas (10). In the present study, none of the patients diagnosed with ICC presented with jaundice compared with $91 \%$ of the perihilar and $87 \%$ of the patients with distal cholangiocarcinoma. The most common presenting complaint for ICC in this series, similar to that in other series noted above $(1,10)$, was abdominal pain ( $61 \%$ of patients).

BCS is the result of obstruction to hepatic venous outflow and should be suspected in various clinical situations that include: ascites, upper abdominal pain and liver enlargement occurring concurrently (11); intractable ascites (12); liver disease occurring in prothrombotic states (13); fulminant liver failure (14-16); and as part of the workup for cryptogenic liver failure (17). The diagnosis of BCS can be confirmed through various imaging modalities including ultrasound, CT scan and magnetic resonance imaging. Tumour causing compression or invasion into the venous lumen and resulting in secondary BCS is very rare; there is a well-documented association between HCC and BCS in the literature. HCC can cause obstruction of the IVC or hepatic veins by mass effect or endoluminal invasion (18). With respect to ICC and BCS, a study of 17 patients from Japan with mass-forming (MF) ICC attempted to correlate the relationship between tumour size and mode of spread of the tumour (19). In this series, patients were classified into one of three groups: tumour size less than $45 \mathrm{~mm}(\mathrm{n}=4), 45 \mathrm{~mm}$ to $80 \mathrm{~mm}$ in size $(\mathrm{n}=7)$ and greater than $80 \mathrm{~mm}$ in size $(\mathrm{n}=6)$. Hepatic vein invasion was not present in patients with tumours less than $45 \mathrm{~mm}$ but increasing incidence was noted with increasing tumour size, with $29 \%$ and $50 \%$ incidence noted in patients with tumour size between $45 \mathrm{~mm}$ and $80 \mathrm{~mm}$ and greater than $80 \mathrm{~mm}$, respectively. However, significant obstruction causing acute or chronic BCS has only been noted in the two previously mentioned patients $(3,4)$.

ICC has been classified based on macroscopic pathology, as suggested by the Liver Cancer Study Group of Japan. There are three fundamental types of ICC: MF type, periductal infiltrating type and intraductal growth (IG) type (20). The most common type of ICC is the MF type. In several series, MF-type ICC accounted for $64 \%$ to $83 \%$ of total patients with ICC (20-23). IG, the type in this patient presentation, is by far the rarest type of ICC in published literature (incidence of $0 \%$ to $7 \%$ in several case series). The IG type is characterized by proliferation within the dilated part of a large intrahepatic bile duct with no, or mild, tumourous extension beyond the bile duct wall. On histology, the majority of ICC are adenocarcinomas; an important characteristic of ICC is the abundant fibrous stroma with small amounts of lymphoid cell infiltrate. Expression of cancer-associated antigens is variable and appears to be associated with tumour size and type; in a multivariate analysis of predominantly MF-type ICC, multiple hepatic lesions and a high serum carbohydrate antigen 19-9 level were independently associated with poor prognosis (24), while in another series, elevated carcinoembryonic antigen was noted in three of nine patients with MF-type ICC (tumours at stages IV-A and IV-B), while alphafetoprotein was noted to be elevated in only one patient in that series (22).

A common characteristic of ICC is the fibrous stroma formation, important in the support and blood supply for the tumour parenchyma. Perisinusoidal cells are important in storing vitamin $\mathrm{A}$ and producing extracellular matrix proteins; these cells respond to liver injury by prompt proliferation and transformation into myofibroblasts which in turn produce extracellular matrix proteins such as collagen, laminin and fibronectin (25). Antismooth muscle actin immunoreactivity (a marker of perisinusoidal cells, myofibroblasts and smooth muscle cells of the vessels of the portal tracts of the human liver) is abundant in ICC and directly correlates with the degree of fibrosis (26). The stromal invasion and metastasis of ICC, in turn, are the result of the expression of several matrix proteinases, including matrix metalloproteinases, pancreatic trypsinogen and cathepsin B, and urokinase-type plasminogen activator. Stromal expression of urokinase-type plasminogen activator by macrophages has been shown by Akahane et al (27) to be associated with invasive growth of cancer cells into the surrounding tissue of primary liver tumours, with higher expression in cholangiocarcinomas compared with HCC. The fibroblasts in the tumour stroma and cancerous cells have been shown to have enhanced expression of thrombosporin-1, an antiangiogenesis factor that may have a role in the relative hypovascularity of ICC (26). This condition has been hypothesized to contribute toward the development of a favourable environment for tumour invasion by ICC.

The understanding on a molecular and genetic level of ICC with respect to its biological behaviour is unclear. However, it is known that several growth factors, including hepatocyte growth factor, c-met, c-erbB-2 and interleukin-6, are overexpressed in neoplastic biliary epithelium, and K-ras and p53 mutations occur (26).

The prognosis for cholangiocarcinoma remains abysmal; however, there appears to be some hope in a selected group of patients with extrahepatic tumours. For unresectable tumours the following transplantation protocol (28) appears to be a significant advance: external beam irradiation along with 5-fluorouracil administration for two to three weeks, followed by luminal radiation using iridium seeds (intraluminal brachytherapy). Patients then undergo a staging laparotomy to determine eligibility for transplantation. Recent data indicate that the actuarial survival for those receiving grafts is $88 \%$ at one year and $82 \%$ at five years after liver transplantation. Unfortunately, patients with ICC are precluded from receiving this form of therapy.

ICC tends to have a poor prognosis because of its typically late presentation. In this case of a rare variant of ICC, the presentation of acute BCS is a reflection of the malignant potential of this cancer and our limited options in the management and treatment of this disease. It is likely to pose a significant challenge because of its globally increasing incidence.

\section{REFERENCES}

1. Chu KM, Lai EC, Al-Hadeedi S, et al. Intrahepatic cholangiocarcinoma. World J Surg 1997;21:301-5.

2. Menon KV, Shah V, Kamath PS. The Budd-Chiari syndrome. N Engl J Med 2004;350:578-85.

3. De BK, De KK, Sen S, et al. Etiology based prevalence of BuddChiari syndrome in eastern India. J Assoc Physicians India 2000;48:800-3.

4. Bandyopadhyay SK, Sarkar N, Ghosh S, Dasgupta S. Cholangiocarcinoma presenting with recurrent venous thrombosis. J Assoc Physicians India 2003;51:824-5.

5. Taylor-Robinson SD, Toledano MB, Arora S, et al. Increase in mortality rates from intrahepatic cholangiocarcinoma in England and Wales 1968-1998. Gut 2001;48:816-820.

6. Wood R, Brewster DH, Fraser LA, Brown H, Hayes PC, Garden OJ. Do increases in mortality from intrahepatic cholangiocarcinoma reflect a genuine increase in risk? Insights from cancer registry data in Scotland. Eur J Cancer 2003;39:2087-92. 
7. Shaib YH, Davila JA, McGlynn K, El-Serag HB. Rising incidence of intrahepatic cholangiocarcinoma in the United States: A true increase? J Hepatol 2004;40:472-7.

8. Olnes MJ, Erlich R. A review and update on cholangiocarcinoma. Oncology 2004;66:167-79.

9. Shaib Y, El-Serag HB. The epidemiology of cholangiocarcinoma. Semin Liver Dis 2004:24:115-25.

10. Nakeeb A, Pitt HA, Sohn TA, et al. Cholangiocarcinoma A spectrum of intrahepatic, perihilar and distal tumours. Ann Surg 1996;224:463-73.

11. Singh V, Sinha SK, Nain CK, et al. Budd-Chiari syndrome: Our experience of 71 patients. J Gastroenterol Hepatol 2000;15:550-4.

12. Okuda H, Yamagata H, Obata H, et al. Epidemiological and clinical features of Budd-Chiari syndrome in Japan. J Hepatol 1995;22:1-9.

13. Valla DC. The diagnosis and management of the Budd-Chiari syndrome: Consensus and controversies. Hepatology 2003;38:793-803.

14. Rakela J, Lange SM, Ludwig J, Baldus WP. Fulminant hepatitis: Mayo Clinic experience with 34 cases. Mayo Clin Proc 1985;60:289-92.

15. Dhiman RK, Seth AK, Jain S, Chawla YK, Dilawari JB. Prognostic evaluation of early indicators in fulminant hepatitic failure by multivariate analysis. Dig Dis Sci 1998;43:1311-6.

16. Acharya SK, Dasarathy S, Kumer TL, et al. Fulminant hepatitis in a tropical population: Clinical course, cause, and early predictors of outcome. Hepatology 1996;23:1448-55.

17. Byron D, Minuk GY. Clinical hepatology: Profile of an urban, hospital-based practice. Hepatology 1996;24:813-5.

18. Vilgrain V, Lewin M, Vons C, et al. Hepatic nodules in BuddChiari syndrome: Imaging features. Radiology 1999;210:443-50.

19. Sasaki A, Kawano K, Aramaki M, Ohno T, Tahara K, Kitano S. Correlation between tumour size and mode of spread in massforming intrahepatic cholangiocarcinoma. Hepatogastroenterology 2004;51:224-8.

20. Yamasaki S. Intrahepatic cholangiocarcinoma: Macroscopic type and stage classification. J Hepatobiliary Pancreat Surg 2003;10:288-91.

21. Itamoto T, Asahara T, Katayama K, et al. Hepatic resection for intrahepatic cholangiocarcinoma: Relation to gross tumour morphology. Hepatogastroenterology 2001;48:1129-33.

22. Sasaki A, Aramaki M, Kawano K, et al. Intrahepatic peripheral cholangiocarcinoma: Mode of spread and choice of surgical treatment. Br J Surg 1998;85:1206-9.
23. Isaji S, Kawarada Y, Taoka H, Tabata M, Suzuki H, Yokoi H. Clinicopathological features and outcome of hepatic resection for intrahepatic cholangiocarcinoma in Japan. J Hepatobiliary Pancreat Surg 1999;6:108-16.

24. Ohtuska M, Ito H, Kimura F, et al. Results of surgical treatment for intrahepatic cholangiocarcinoma and clinicopathological factors influencing survival. Br J Surg 2002;89:1525-31.

25. Terada T, Makimoto K, Terayama N, Suzuki Y, Nakanuma Y. Alpha-smooth muscle actin-positive stromal cells in cholangiocarcinomas, hepatocellular carcinomas and metastatic liver carcinomas. J Hepatol 1996;24:706-12.

26. Nakanuma Y, Harada K, Ishikawa A, Zen Y, Sasaki M. Anatomic and molecular pathology of intrahepatic cholangiocarcinoma. J Hepatobiliary Pancreat Surg 2003;10:265-81.

27. Akahane T, Ishii M, Ohtani H, Nagura H, Toyota T. Stromal expression of urokinase-type plasminogen activator receptor (uPAR) is associated with invasive growth in primary liver cancer. Liver 1998;18:414-9.

28. Heimbach JK, Haddock MG, Alberts SR, et al. Transplantation for hilar cholangiocarcinoma. Liver Transpl 2004;10:S65-8.

29. Sharma MP, Ahuja V. Aetiological spectrum of obstructive jaundice and diagnostic ability of ultrasonography: A clinician's perspective. Trop Gastroenterol 1999;20:167-9.

30. Bloom CM, Langer B, Wilson SR. Role of US in the detection, characterization, and staging of cholangiocarcinoma. Radiographics 1999;19:1199-218.

31. Valls C, Guma A, Puig I, et al. Intrahepatic peripheral cholangiocarcinoma: CT evaluation. Abdom Imaging 2000;25:490-6.

32. Tillich M, Mischinger HJ, Preisegger KH, Rabl H, Szolar DH. Multiphasic helical CT in diagnosis and staging of hilar cholangiocarcinoma. AJR Am J Roentgenol 1998;171:651-8.

33. Manfredi R, Barbaro B, Masselli G, Vecchioli A, Marano P. Magnetic resonance imaging of cholangiocarcinoma. Semin Liver Dis 2004:24:155-64.

34. Guibaud L, Bret PM, Reinhold C, Atri M, Barkun AN. Bile duct obstruction and choledocholithiasis: Diagnosis with MR cholangiography. Radiology 1995;197:109-15.

35. Sugiyama M, Hagi H, Atomi Y, Saito M. Diagnosis of portal venous invasion by pancreatobiliary carcinoma: Value of endoscopic ultrasonography. Abdom Imaging 1997;22:434-8.

36. Khan SA, Davidson BR, Goldin R, et al. Guidelines for the diagnosis and treatment of cholangiocarcinoma: Consensus document. Gut 2002;51(Suppl 6):VI1-9. 


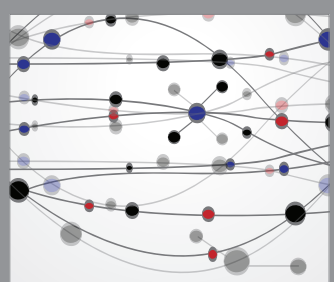

The Scientific World Journal
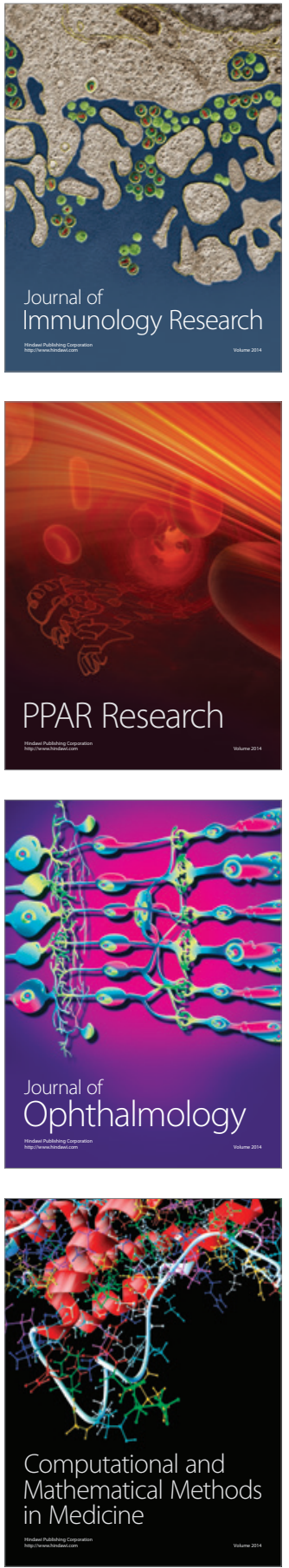

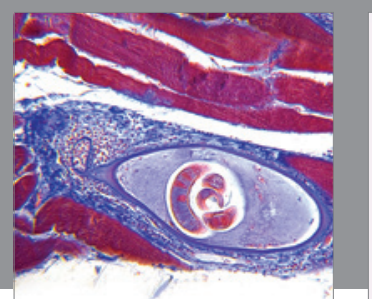

Gastroenterology Research and Practice

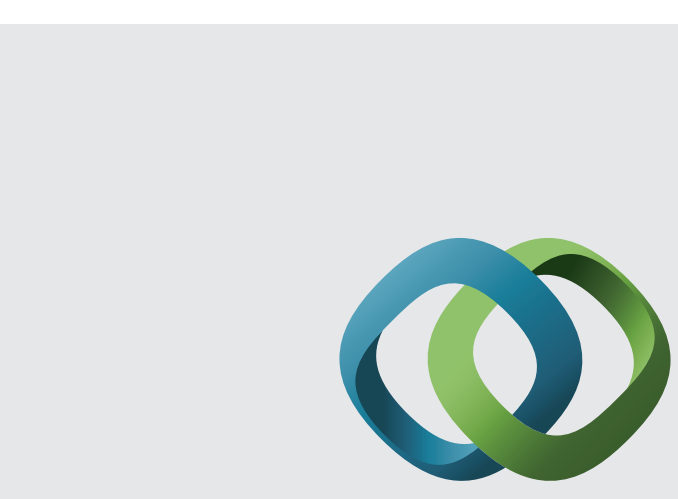

\section{Hindawi}

Submit your manuscripts at

http://www.hindawi.com
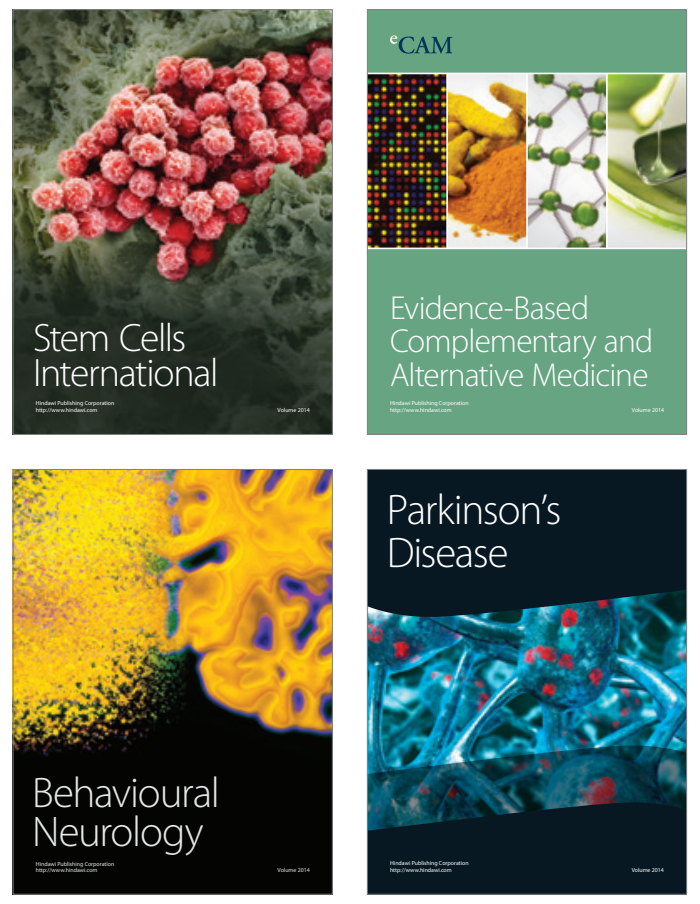
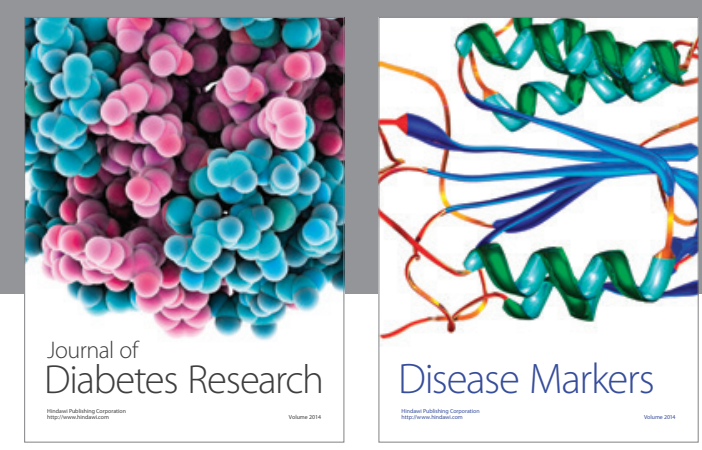

Disease Markers
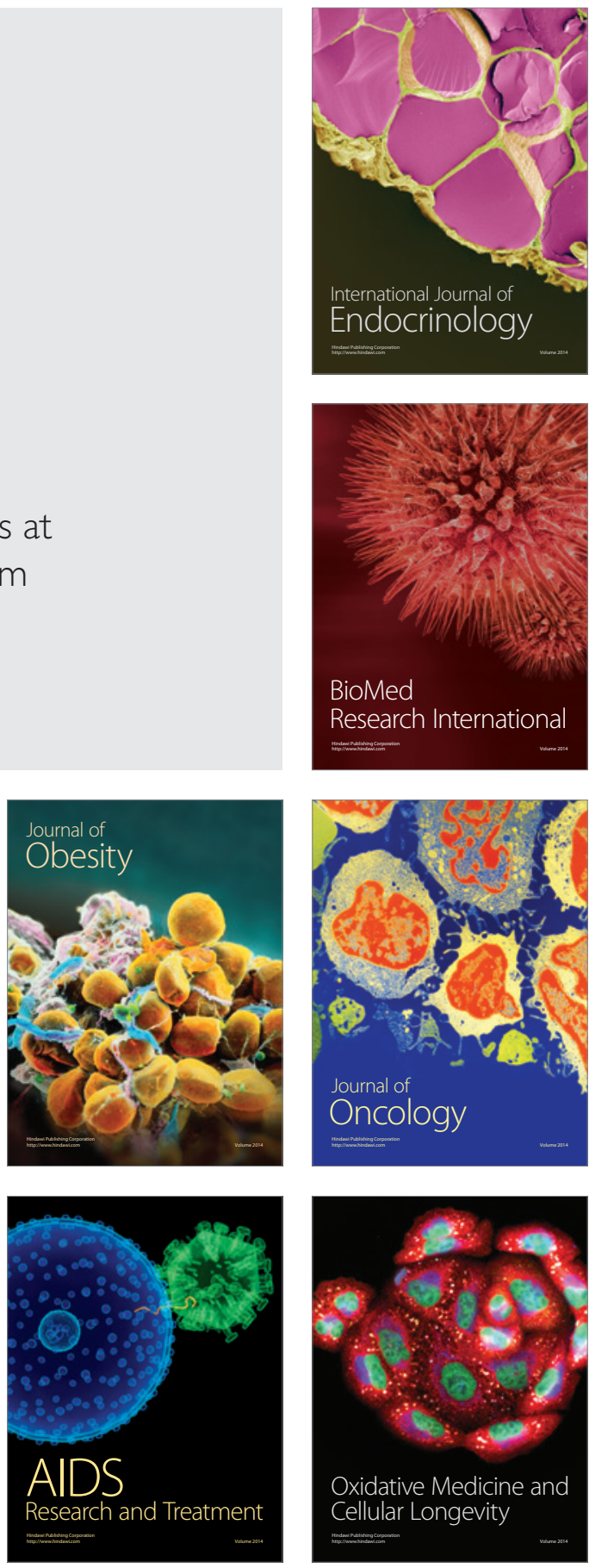